\title{
Child Marriage in Nepal: Stakeholders' Perspective
}

\author{
Kamal Gautam, PhD*
}

\begin{abstract}
This study is about child marriage in Nepal from stakeholder's perspective. It includes school going girls, women, teachers, health post staffs and local politicians as stakeholders and intends to find the situation, effects and perfectives of stakeholders on child marriage in Nepalese context. It comprises both qualitative and quantitative aspects followed by interview schedule and FGDs as tools. Fathers, relatives and friends were responsible for the incidence of early marriage in study site. Regarding effects, problems to become selfdependent and deprivation of opportunity are the major effects that respondents had to face in their life. Workload in the families seems another effect to be faced followed by health problems to be experienced. Bleeding during pregnancy, low count of RBC, weakness, postpartum complications were seen in mothers during and after child births. Teenage mothers being more likely to experience complications during pregnancy and less likely to be emotionally, physically and psychologically prepared to deal with pregnancy related challenges, which often leads to maternal illness and consequently death was seen as the main conclusion of this study.
\end{abstract}

Keywords: Child marriage, complications of child marriage, stakeholders' perspective

\section{Introduction}

Child marriage is a global problem which affects millions of people across the world. It is considered a human right violation because it deprives especially girls of education and health services, the chance to learn skills and develop their potentialities, and leaves them vulnerable indeed (World Vision International Nepal, 20I2). Bajracharya (20I4) opines that child marriage restricts children's choice, changing their course in life, and putting them at significant risk of abuse and violence.

Marriage occurs relatively early in Nepal. According to a report of MoHP (201 I), 55 percent girls are married by age 18 and 74 percent are married by age 20 . The median age at first marriage among women age $25-49$ is 17.5 years. The proportion of women married by age 15 declines from 24 percent among those age 45-49 to 5 percent among those age 15-19 indicating clear evidence of a rising age at first marriage.

Nepal is one of the highest rates of child marriage in Asia. Although the legal age of unions for both sexes is 20 years, the report of CSB (2015) shows that more than a third of young women are married at the age of 18 . The concept of early marriage as Ahmad (2012) states, is synonymous with the women's new gender-defined role of motherhood which is a cultural expectation emanating from the husband and the in-laws and often women's own parents. He

\footnotetext{
* Associate Professor, Central Department of Education, Tribhuvan University, Kirtipur, Kathmandu Email: kamalgautamktm@gmail.com
} 
has mentioned that nearly one quarter $(23 \%)$ of the women by the age of 19 years is childbearing in the world. He further has added that high rate of early age marriages is compounded with the common practice of early conception of the first pregnancy, which is culturally considered to be a sign of fertility.

A child education is also significantly affected with married girls in Nepal 10 times more likely not to be school than their unmarried peers (MoHP, 2012). The same report discloses that girl's right to health also comes under threat stating that just over one in eight Nepali women had babies before the age of 18 which puts them at a higher risk of death or injury during child birth. However, as UNICEF report (2017) states, poverty, the low value attached to daughters and lack of access to education are contributing factors behind it.

The study site of this research is a village situated at western part of Nepal. It falls under Panini Gaunpalika of Argakhanchi district and is known as Sadhanbutta. The village is surrounded by Debalchour in east, Khulaule in west, Dhairchaur in the south and Dhaba in the north. It lies in province no. 5. According to its ward profile of 2074 B.S. as maintained by local mother's group, it has 109 households and 676 populations in total. The major caste people are Brahmin, Magar and Dalits. Like in other parts of the country, prevalence of teen age marriage is still found in the village though it is known somehow as an educated place in the district.

\section{Rationale of the Study}

Child marriage has numerous adverse effects on the overall wellbeing of children who are mentally, psychologically, emotionally and physically unfit for married life. But in Nepal, child marriage is a customary, socially established practice that has been carried on for generations. According to World Vision International Nepal (2018), only $48.84 \%$ female and $59.63 \%$ male are literate in Nepal that means still significant portion of population is illiterate. Ignorance, old-age tradition and customs are not easy to do away with. Unless people are made aware of the devastating multi-pronged effects of early marriage, they will not strive to eliminate it from society. This situation clearly demands stakeholders' perspectives on early marriage in Nepalese context and this has led me to choose this area for the study. The study aimed to find out the situation of child marriage at study site and explore the perspective of survivors about early marriage.

\section{Methods}

The study was based on mixed design. The researcher had used both qualitative and quantitative methods to collect information required for this study. The study populations for this study were mainly the school attending girls and the married women who were 15 to 24 years of age. Moreover, some other stakeholders like school teachers, elected local politicians and the in- charge of the local health post were interviewed. The total number of respondents were II4, out of which 100 girls and women of 15 to 25 years of age, 08 school teachers from local school, 2 staffs (male and female) from local health post and 03 elected ward members including the ward chairperson were chosen by purposive sampling technique.

Required information was taken by applying interview and FGD. The respondents were taken individual interview and four FGDs among girls and women, school teachers, and health post 
staffs and newly elected politicians at ward level. Before making final tools, sample of interview schedule was developed and administrated among 20 respondents as pre-test and was analyzed minutely. It was then improved as per need and FGD guideline was prepared upon objectives to be achieved. To ensure rapport relationship, an informal sharing with different stakeholders was organized to develop the understanding of the whole process of data collection.

The data collected from the respondents were entered in SPSS program. Then the data were tabulated and calculated using SPSS and MS Excel program. However, for qualitative data, thematic analysis was used.

Under ethical consideration, working relations with stakeholders was strictly maintained. Privacy, use and protection of information, respect to different customs and culture were strictly maintained within the premises of research ethics.

\section{Results}

\section{Information Regarding Marriage}

The married respondents were asked individually at what age they were married themselves. Out of 78 married respondents, 39 respondents said that they were married before 18 years of age, 19 respondents before 20 and about 19 after 20 years. It shows that majority of respondents themselves were married before legal age as declared by Nepalese law. Regarding the persons who were responsible behind marriage as respondents told was as following:

Table I

Responsible Person for Early Marriage

\begin{tabular}{lll}
\hline Responsible Person for ECM* & $\begin{array}{l}\text { Number } \\
\text { of respondents }\end{array}$ & Percent \\
\hline Father & 29 & 42.64 \\
Mother & 12 & 17.64 \\
Self-eloped & 14 & 20.58 \\
Lover & 03 & 4.41 \\
Friends & 17 & 25.0 \\
Other relatives & 19 & 27.94 \\
\hline
\end{tabular}

* Multiple responses

The above table shows that fathers, relatives and friends were responsible for their early marriage. It also shows reality of power dynamics in the families and community. While doing FGDs the women respondents who were compelled to do marriage against their intension expressed that:

We were not even informed about our marriage. It was decided by our family members.

We did not have even choice to refuse the proposal. This happens even now in most of the families though it seems decreasing.

School teachers in the same regard said that they always tried their best to postpone marriages and even got success in some cases but for this they had to be informed prior to 
marriage. However, they opined that the trend is decreasing day by day. Regarding same perspective, school girls said that:

Time has changed now and nobody can impose us to do against our wish. However, we have to be careful to convince our parents that early marriage causes several damages in our life.

The staffs of local health post and locally elected members in the same regards viewed that it used to happen in the past but now it has become liberal and parents seen less dominant to their siblings. Pressure groups in the community have played worthy role to convince parents in need.

\section{Effects of Child Marriage}

In order to find effects of child marriage, the respondents were asked about types of effect that they had to bear at personal level. They responded as following:

Table 2

Effects of child marriage

\begin{tabular}{lll}
\hline Effects of Child Marriage & $\begin{array}{l}\text { Number } \\
\text { of respondents }\end{array}$ & Percent \\
\hline Health problem including sickness and injuries & 28 & 41.17 \\
Problem during pregnancy & 17 & 25.00 \\
Workload in the families & 42 & 61.76 \\
School drop-out & 06 & 08.82 \\
Deprivation of opportunity & 49 & 72.05 \\
Problems in self-dependent & 56 & 82.35 \\
\hline
\end{tabular}

*Multiple responses

If we see the response that is shown in table no. 2 , it is seen that problems to become selfdependent and deprivation of opportunity are the major effects that respondents had to face in their life. Workload in the families seems another effect to be faced followed by health problems to be experienced.

Pregnancy related complications seem another risk that happened among significant number of respondents. It indicates that the respondents, who got early marriage for various reasons, had to face many challenges at personal level and in the families. While doing FGD these school girls said,

We have witnessed several problems among those who were either compelled to do marriage against their will or did marriage on their own. Problem ranges from dependency to various health problems. Some cases even have to face domestic violence and breakups. Problems are most visible in poor families.

This version reveals about various effects caused by early marriage in study area. Regarding maternal morbidity in the household, $51.28 \%$ said that they had to face bleeding during their pregnancies, while $10.25 \%$ reported postpartum bleeding and $16.66 \%$ complications during pregnancies. Likewise, $37.17 \%$ reported less RBC and weakness during pregnancy. This shows that early marriage can contribute to maternal morbidity in many ways.

Regarding child morbidity, $26.92 \%$ respondents said that they had to bring their children to health facilities for treatment for different diseases. For them, it was due to their workload in 
the families that caused less focused on their children. Out of total mothers, $5.12 \%$ had to face even miscarriage during their prenatal periods.

Respondent's perspective

Incidence of teen age marriages and pregnancies continue to be significant among all the caste groups. Although the government of Nepal considers 20 as an eligible age for marriage among couples, there were incidences where couples in all caste communities got marriage before they turned to 20 years. Teenage marriages and pregnancies were found prevalent among all caste groups though it seemed more or less among them. However, the practice as said by the respondents was on downwards. They opined that the situation still warrants continuing attention and intervention.

Regarding the perception on age of marriage, Dalit and Magar informants were found to be in favor of early marriage in comparison to the Brahmin informants. In addition, the Dalit informants preferred certain age difference between couples about to get married. The scenario was somewhat different in Brahmin and Magar communities, as they were found to accept same age marriage partner. However, one thing to be noted from the finding is that the young informants of all the ethnic communities seemed increasingly to be in favor of delayed marriage. This was an indicator of a progressive trend towards delayed marriage.

\section{Discussion}

The highest rate of early marriage is seen in Southern Asia. UNICEF (2014) states $56 \%$ in Southern Asia, $46 \%$ in Central and Western Africa and only 14\% in Central and Eastern Europe. The report of this scenario is $52 \%$ in Nepal. Gautam (20I6) states that women with no or less education and living in rural areas are more likely to be married as compared to those living in urban areas. However, a research conducted on behalf of Plan Nepal, Save the Children and World Vision International Nepal (2012) presents a bit different situation. The report shows average prevalence of child marriage among both sexes less than fifty percent (46.2\%). It is perhaps due to the different contexts of study. However, the report states similar finding of high prevalence of early marriage among Janjatis and dalits.

Gangoli and Chantler (2009) find families and belonging communities as decision makers behind child marriage incidence. However, Danna (2009) sees the eligibility requirement of marriage contextual to belonging culture, country or even regions.

Winkiest and Akhtar (2000) view early marriage from high fertility perspective adding that age at first marriage has a marked effect on childbearing because women who marry early have, on average, a longer period of exposure to the risk of becoming pregnant and a greater number of lifetime births. Silwal (20II) point outs the complications to be faced by mothers stating that some women lose the fetus even before being born or shortly after birth, while some lose both their life and that of the baby.

Ahmad (2012) states early age at child-bearing has negative ramifications on the women's and child's health. These factors are known to be associated with multiple adverse health conditions both for the women in this age group and for the newborns. 


\section{Conclusion}

The issue of child marriage at present is still seen critical. Early age at child-bearing has negative ramifications on the women's and child's health. These factors are known to be associated with multiple adverse health conditions both for the women in this age group and for the newborns. The adverse health conditions include, first children born to young mothers being more predisposed to illness and death. Second, teenage mothers being more likely to experience complications during pregnancy and less likely to be emotionally, physically and psychologically prepared to deal with pregnancy related challenges, which often leads to maternal illness and death. Third, their early entry into reproduction and child bearing denies them the opportunity to pursue academic and/or professional goals and is simply inhibitive to any prospects of professional careers. This conclusion reveals that though the informants' beliefs are becoming increasingly progressive on marriage and pregnancy, the practice of child marriage is still prevalent in the study site.

\section{References}

Ahmad, A.M. (2012). Primary antenatal care services, maternal health and birth outcomes in rural Pakistan. A PhD dissertation submitted to the Faculty of Medicine, Dentistry and Health Science. Australia: The University of Melbourne

Bajracharya, (20I4). Nepal adolescent's development and participation baseline survey. Final report, Population Council. New York, 2014

Central Bureau of Statistics (Nepal) and UNICEF, Nepal (2015). Nepal Multiple Indicators Cluster Survey, 20 I4: Final report. CBS, Kathmandu.

Danna, D. (2009) from http://ijfs.padovauniversitypress.it/system/files/papers/20_I_03.pdf

Gangoli, G. \& Chantler, K. (2009). Protecting victims of forced marriage: Is age a portative factor? Feminist Legal Studies, 12 (17) 266-288

Gautam, K. (2016). Practice and perception of people on maternal health. An unpublished PhD dissertation submitted to the Faculty of Education, Tribhuvan University, Nepal.

Maharjan, R.K., Karki, K.B., Shakya, T.M. \& Aryal, B. (20I2). Child Marriage in Nepal. Retrieved from https:/www.wvi.org/sites/default/files/Child\%20Marriage \%20in\%20Nepal\%20Report.pdf

MoHP (20II). Annual report: Department of Health Services $2066 / 67$ (2009/2010).Kathmandu, Nepal: Ministry of Health and Population.

O'Hara, K.J. (2019). Literacy Rates are improving in Nepal. Retrieved from https://www.worldvision.org/education-news-stories/literacy-rates-improving-nepal

Silwal, M. (20I I). Maternal health care practices among indigenous people of Nepal: A case study of the Raute community. Master of Philosophy in Indigenous Studies, Faculty of Humanities, Social Sciences and Education University of Tromsø.

UNICEF (2014). Ending child marriage: progress and prospects. New York: UNICEF

UNICEF (2017). Effect of child marriage on girls, dropouts in Nepal: analysis of data from the multiple indicators clusters survey. UNICEF Nepal working paper series, 2017.

Winkvist, A. and Akhtar, H. Z. (2000). "God should give daughters to rich families only: Attitudes towards childbearing among low-income women in Punjab, Pakistan." Social Science and Medicine 5I: 73-8I. 